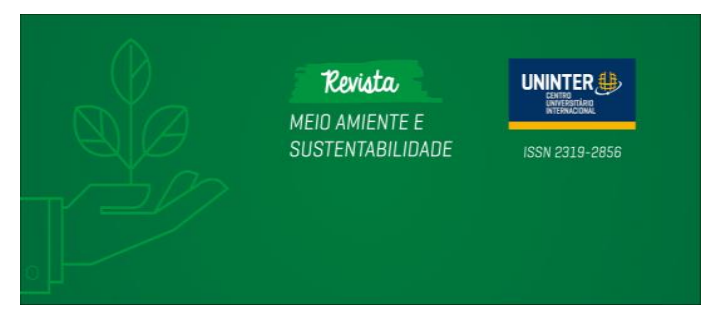

Revista Meio Ambiente e Sustentabilidade

Versão on-line ISSN 2319-2856

Volume 15, número 7. Curitiba - PR. jun/dez -

2018

\title{
Tecnologias para Reciclagem de Sistemas Fotovoltaicos: Impactos Ambientais
}

Thays Fernandes Coelho thays.fercoelho@gmail.com

Universidade Federal de Tocantins

\author{
Juan Carlos Valdés Serra \\ juancs@uft.edu.br
}

Universidade Federal de Tocantins

\section{RESUMO}

As fontes de energias fosseis vem cada vez mais sendo discutidas, devido a degradação que a mesma causa ao meio ambiente, por isso a buscar por novas fontes renováveis e limpa vem crescendo no mundo, dentre essas fontes está a energia solar, que é a conversão da luz solar em energia. Este artigo tem como objetivo fazer uma pesquisa das tecnologias que são usadas para reciclagem de painéis fotovoltaicos, caracterizando os processos de quebrar dos módulos e a recuperação dos vários materiais. Para isso será usados pesquisas metodológicas em literatura portuguesa e inglesa para se discorrer sobre o assunto, como ocorre a quebra desses materiais, quais são as principais tecnologias empregadas na reciclagem dos módulos e seus benefícios. É mostrado que um dos maiores benefícios são os ambientais e a viabilidade econômica que são importantes para o estabelecimento de sistemas de reciclagem fotovoltaicos.

Palavra-chave: Células fotovoltaicas, energia limpa, modulo de silício, tratamento químico e físico. 


\section{Technologies For Recycling Of Photovoltaic Systems: Environmental Impacts}

\section{ABSTRACT}

The sources of fossil energy are increasingly being discussed, due to the degradation that causes the same to the environment, so to search for new and clean renewable sources is growing in the world, among these sources is solar energy, which is the conversion from sunlight into energy. This article aims to make a research of the technologies that are used for recycling of photovoltaic panels, characterizing the processes of breaking of the modules and the recovery of the various materials. For this, methodological researches will be used in Portuguese and English literature to discuss the subject, such as the breakdown of these materials, which are the main technologies used in the recycling of the modules and their benefits. It is shown that one of the greatest benefits are the environmental and economic viability that are important for the establishment of photovoltaic recycling systems.

Keywords: Photovoltaic cells, clean energy, silicon module, chemical and physical treatment.

INTRODUÇÃO

As principais fontes de energia ainda são proveniente dos combustíveis fosseis, que além de serem finitos, acabam degradando o meio ambiente devido ao seu uso desenfreado. Com a crise energética e a continua degradação do meio ambiente há a necessidade de desenvolver tecnologias para energias limpas e renováveis, dentre estas tecnologias disponíveis, a energia solar destaca-se como uma possibilidade promissora e confiável. (BETTANIN, 2017)

A transformação de energia fotovoltaica é uma das tecnologias largamente considerada como renovável e com grande potencial de fornecimento de energia limpa, sustentável e que, pode amenizar as emissões de gases prejudiciais ao meio ambiente e a saúde humana. (ALSEMA E NIEUWLAAR, 2000)

Com o grande crescimento no desenvolvimento e utilização desse recurso, as placas solares passaram a ser uma fonte de energia de rápido crescimento. E a medida que a indústria de energia solar cresce, há uma questão iminente de gerenciamento de resíduos (BETTANIN, 2017).

Um modulo fotovoltaico tem vida útil entre 25-30 anos e ao longo desse ciclo de vida completo, embora em menor grau do que as fontes de energia tradicionais, as placas fotovoltaicas também criam resíduos sólidos. Uma das principais questões para o descarte das placas são, a falta de tecnologia adequada de recuperação e o 
risco de liberação de substâncias perigosas que podem contaminar o meio ambiente e ameaçar a saúde humana, se a fase de fim de vida não for gerenciada sagazmente (KIDDEE ET AL., 2013).

Segundo a Agencia Internacional de Energia (IEA) a Europa é o continente que tem a maior capacidade instalada de painéis fotovoltaicos, representando $70 \%$ do total do mundo inteiro, e com uma estimativa de 9,57 milhões de toneladas em 2050 (Serviço de Bio-Inteligência (BiolS)). Para limitar o possível impacto negativo do crescimento previsto nos resíduos fotovoltaicos, a comissão da União Europeia (UE) decidiu recentemente incluir os painéis fotovoltaicos na nova diretiva relativa aos resíduos de equipamentos elétricos e eletrônicos (SHIN, e col. 2017 Apud Y. Qu e col. 2013).

São identificados algumas gerações para a tecnologia de placas fotovoltaicas na indústria, na qual a primeira geração correspondem a tecnologia com silício cristalino. A segunda geração é a que provem de filmes finos inorgânicos, como exemplo: CdTe, disseleneto de cobre e índio (CIS), disseleneto de cobre, índio e gálio (CIGS) e silício amorfo (a-Si). Já a terceira geração tem uma tendência de incluir tecnologias orgânicas, pontos quânticos (PQs), células tandem/multijunção, células de portadores quentes (hot carriers), células solares sensibilizadas por corantes (DSSC) e tecnologias de upconversion. (ELY E SWART, 2014).

As tecnologias de tratamento químico e físico, são alguns dos métodos usados para a reciclagem de painéis fotovoltaicos de silício. Porém há poucas informações sobre tais estudos e sobre seus impactos ambientais durante o processo de reciclagem (LATUNUSSA e col., 2016).

O artigo tem como objetivo fazer um levantamento das tecnologias de reciclagem de painéis fotovoltaicos, envolvendo os processos de quebrar dos módulos e a recuperação dos vários materiais que o compõem. Caracterizar os materiais presentes nos componentes dos módulos fotovoltaicos a fim de selecionar os métodos de separação de materiais mais apropriados e mostrar os impactos ambientais provocados com o crescimento da utilização de painéis fotovoltaicos. 


\section{METODOLOGIA}

O presente artigo teve como base para a sua realização, pesquisas bibliográficas feita em artigos científicos em português e inglês que relatam sobre o tema de tecnologias de reciclagem de sistemas fotovoltaicos. Nele é abordado quais tecnologias são empregadas para a reciclagem, o tipo de tratamento utilizado (químico e físico) para recuperação de alguns materiais e os possíveis benefícios que essa tecnologia acarreta no ambiente.

\section{PAINÉIS FOTOVOLTAICOS: TIPOS}

As células fotovoltaicas são feitas de materiais semicondutores que apresentam um arranjo de módulos responsáveis por realizar a transformação de luz solar em energia elétrica, no qual o elétron salta para a banda de condução quando tem uma energia suficiente fornecida pelo sol, e é nesse momento que a energia elétrica é gerada pelos condutores dos módulos. (FRAIDENRAICH; LYRA, 2012).

A tecnologia fotovoltaica, baseia-se em um processo em que um material semicondutor é adaptado para liberar elétrons, as partículas negativamente carregadas que formam a base da eletricidade. Todas as células fotovoltaicas têm, pelo menos, duas camadas de tais semicondutores, uma positiva e outra negativamente carregada. Quando a luz do sol atinge o semicondutor, o campo elétrico entre a junção das duas camadas inicia um fluxo de energia, gerando corrente contínua. (GHIZONE, 2016)

Entre os materiais semicondutores disponíveis, o mais empregado na produção dos módulos é o silício, que atinge cerca de $95 \%$ de todos os módulos fotovoltaicos no mundo (DGS, 2008). O uso predominante desse material para a fabricação de módulos se deve ao bom domínio de sua tecnologia, ao seu alto rendimento relativo, e à sua abundância na superfície da Terra (CHIVELET, 2010).

Existem três tecnologias aplicadas para a produção de módulos fotovoltaicos, classificados em três gerações de acordo com seu material e suas características. A classificação por geração divide os módulos em três grupos: os de $1^{\mathrm{a}}, 2^{\mathrm{a}}$ e $3^{\mathrm{a}}$ geração. (WU et al., 2005). 
FIGURA 1: Células fotovoltaicas de $1^{\circ}, 2^{\circ}$ e $3^{\circ}$ geração.

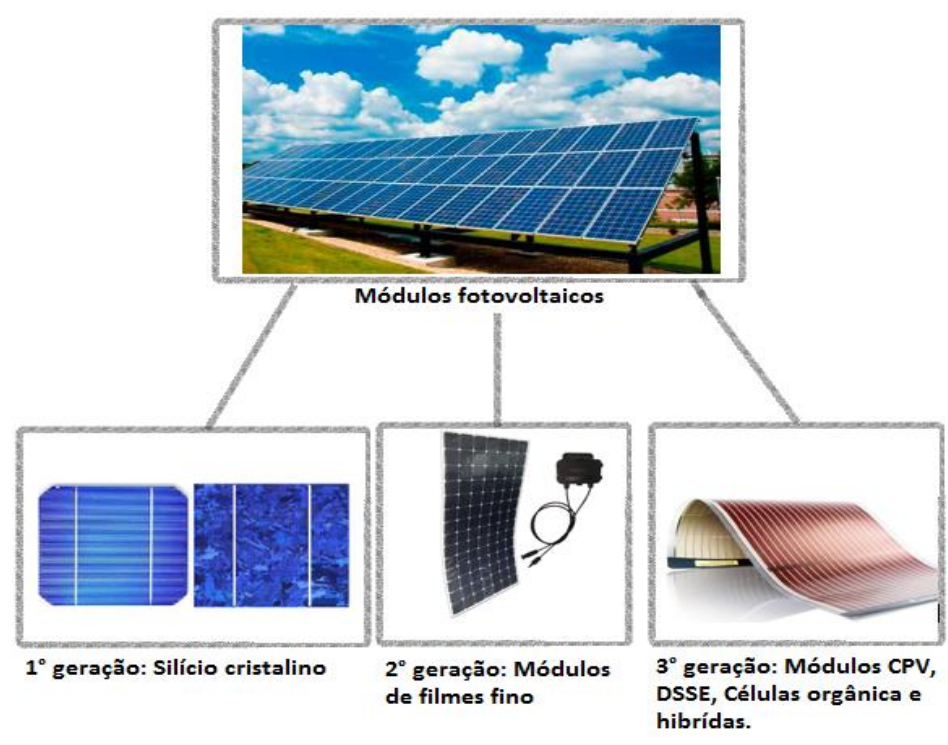

Fonte: Adaptado de SOLAR, 2018.

Módulos de silício cristalino $-1^{\circ}$ geração

A primeira geração é formada pelo silício cristalino, que pode ser dividido em silício monocristalino e silício policristalino. O silício monocristalino é muito mais eficiente, porém mais caro devido ser resultado do fatiamento de um único cristal (SANTOS, 2013). Sua rede cristalina é quase toda homogenia apresentando assim poucas imperfeições (CRESESB, 2010). De acordo com Ruther (2004) os módulos de silício policristalino apresentam uma eficiência inferior se comparados ao monocristalino, apesar de o material de fabricação ser o mesmo, isso porque o silício policristalino é fundido e solidificado, o que resulta em um concentrado com maiores imperfeições. A figura 1 ilustra os tipos de silício cristalino utilizados a fabricação das células fotovoltaicas. 
FIGURA 2: Módulos de silício

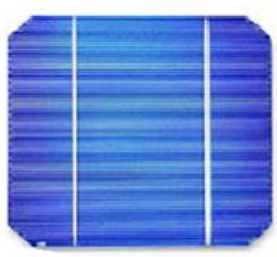

Célula de silicio monocristalino

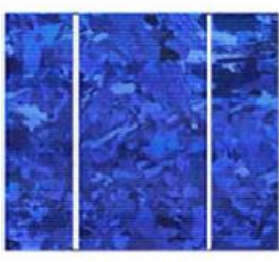

Célula de silicio policristalino

Fonte: Adaptado de ANDREOTTI (2018).

Módulos de filme fino $-2^{\circ}$ geração

A segunda geração é feita de diferentes materiais, como silício amorfo, disseleneto de cobre, índio e gálio, e telureto de cádmio, além de possuir uma ou várias camadas de materiais fotovoltaico por cima de um substrato, como vidro, plástico e ácido inoxidável. O baixo custo desses filmes é uma grande vantagem, e isso se deve ao fato de consumir menos matéria prima e menos energia durante a fabricação, seu processo de fabricação também é mais simples podendo ser produzido em larga escala. (VILLALVA \& GAZOLI, 2012). Todavia a sua eficiência é menor em comparação as células de cristais único de silício (GORE, 2010). Na figura 3 temos é apresentado um modulo de filme fino que é um dos matérias que compõem os módulos de $2^{\circ}$ geração.

FIGURA 3 - Módulos de filmes finos

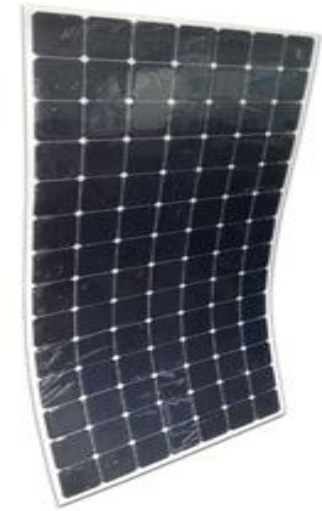

Fonte: Adaptado de SOLAR, 2018 
Módulos CPV, DSSC, Células orgânicas e híbridas - Terceira geração

Os módulos de terceira geração são os módulos de CPV (concentrator photovoltaics), os módulos DSSC (Dry-sensitised solar cell), as células orgânicas e as células híbridas. Esses módulos tem uma utilização de maior eficiência da luz solar, o que a torna altamente eficiente, com baixo custo e utilização de um maior número de materiais sendo estes de baixa toxidade. (VÉRONIQUE MONIER, 2011).

O CPV utiliza lentes para focar a luz do sol e utiliza células de silício ou compostos do grupo III-V, como GaAs. Os DSSC são módulos sensibilizados por corantes e são compostos por materiais orgânicos e inorgânicos como TiO2. As células orgânicas são compostas geralmente por materiais poliméricos ou pequenas moléculas orgânicas finalmente, as células híbridas são células que combinam o silício cristalino e silício amorfo (Ghizoni, 2016 Aput WU et al., 2005). A figura 4 mostra os painéis fotovoltaicos dos módulos de $3^{\circ}$ geração e a sua divisão em CPV, DSSC, células orgânicas e hibridas.

FIGURA 4 - Modulo solar de terceira geração

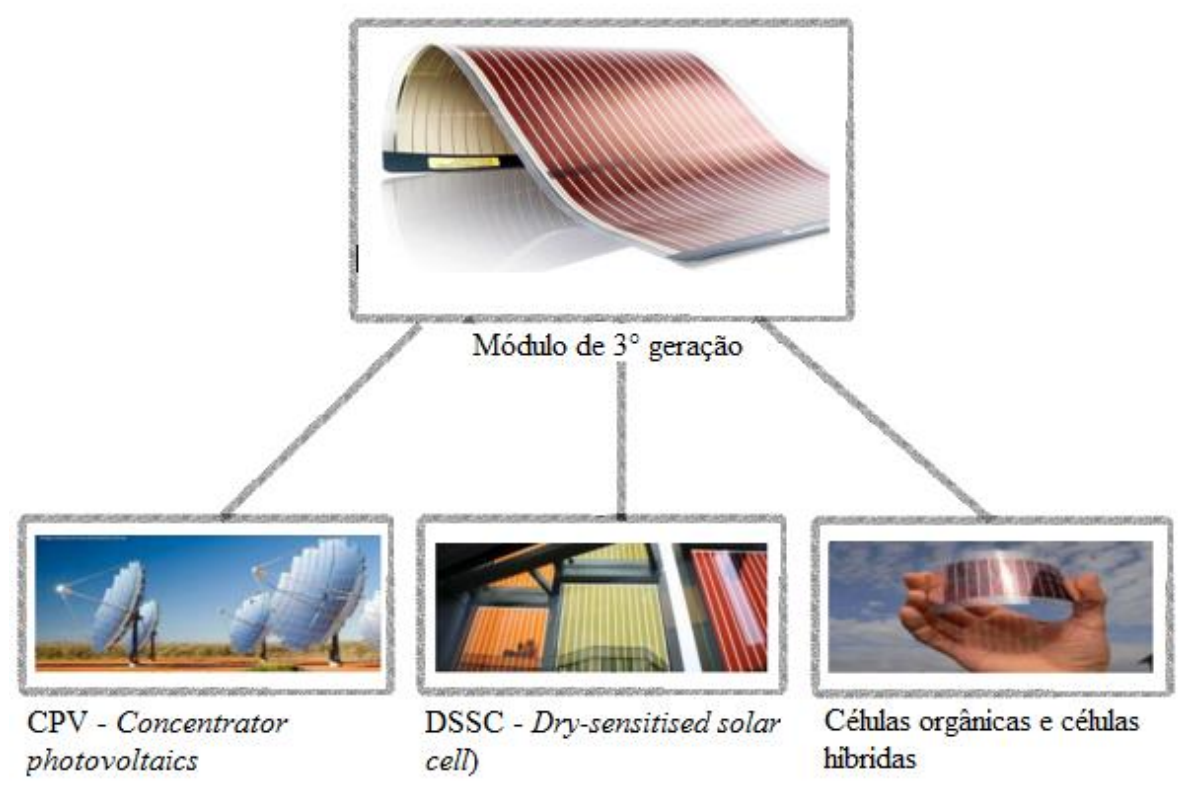

Fonte: Adaptado de SOLAR, 2016 
Componentes do módulo de silício cristalino

Por ser o semicondutor mais empregado atualmente, será descrito a seguir a composição das diversas camadas que possui um modulo fotovoltaico de silício cristalino, como pode ser observado na figura 5.

FIGURA 5 - Componentes das camadas de um modulo de silício cristalino

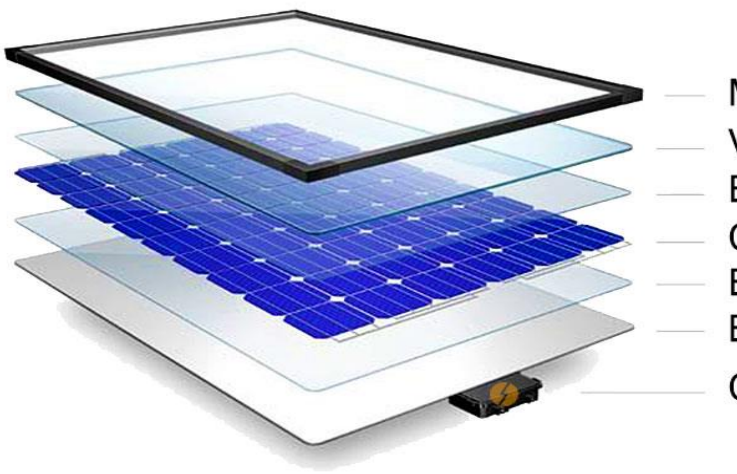

Moldura de Alumínio

Vidro Especial

Encapsulante - EVA

Células Fotovoltaicas

Encapsulante - EVA

Backsheet

Caixa de Junção

Fonte: SOLAR, 2016

O modulo fotovoltaico tem sua camada superior envolvida por um vidro especial temperado, este tem o objetivo de que haja uma menor reflexão e que seja possível deixa passar o máximo de luz através dele. Logo em seguida vem o material de encapsulamento conhecido como EVA - Ethylene Vinyl Acetat, este vai protege o modulo contra as adversidades causadas pela temperatura extrema, umidade, assim como garantir o máximo de incidência solar nos módulos fotovoltaicos (SOLAR, 2016).

Há diferentes contatos metálicos para que possa ocorrer a corrente elétrica. Esse contatos são de importância na reciclagem dos módulos, pois podem conter materiais preciosos e recicláveis, além de ser reutilizável o que acarretara na economia de energia, corte dos gastos e minimização dos impactos no ambiente (DIAS, 2015).

Entre duas camadas de material encapsulante juntamente com os contatos metálicos é colocado a célula voltaica que faz a conversão da luz solar em energia elétrica (BROUWER; GUPTA; HONDA, 2011). O blacksheet que fica na parte de trás da 
célula agi como um isolante elétrico, além de proteger os componentes dentro do modulo (SOLAR, 2016).

Para que o modulo seja resistente e tenha leveza, no final de todo o processo de fabricação do mesmo é colocado ao seu redor uma moldura de alumínio que irá estruturar o painel, e a selagem entre o vidro e a moldura é feito por seletores de silicone ou polibutil (JOHN PERN, 2008).

Descarte dos painéis fotovoltaicos

Os módulos fotovoltaicos quando são descartados enquadram-se como resíduos REEE - Resíduos de Equipamentos Eletro-Eletrônicos. O potencial destes em contaminar o solo constitui um problema ambiental devido a liberação de algumas substâncias toxicas, por isso, deve ser separado dos resíduos sólidos comuns e seu descarte se tratado de forma especial (BETTANIN, Andrea, 2017).

O descarte de painéis fotovoltaicos deve ser feito e gerenciado de uma forma correta, pois se feito de uma forma inadequada e sem tratamento adequado o mesmo pode causar impactos negativos ao ambiente e também a saúde humana. Os impactos estão relacionados com a lixiviação de matérias tóxicos como o chumbo e o cádmio, e com a perda de alguns materiais preciosos como prata, índio, gálio, germânio, e ainda materiais convencionais como alumínio e vidro. (Véronique MONIER. 2011).

Os módulos fotovoltaicos de acordo com estudo feito, foram considerados como resíduos sólidos perigosos classe I, segundo a norma NBR10004. Em vista disso, se não houver um procedimento de reciclagem para os módulos após seu descarte, estes devem ser descartados junto aos resíduos industriais perigosos, não podendo ser descartados com resíduo sólido municipal comum. Diante disso há uma importante razão para se estudar a reciclagem destes dispositivos após seu uso. (BETTANIN, Andrea, 2017).

De acordo com Cyrs et al, (2014), o descarte de módulos fotovoltaicos ainda não está representando um risco eminente a saúde no volume de produção atual, porém deve-se ter um controle, que será importante para gerenciar o fim de vida dos módulos. 
Analise dos impactos ambientais

Como já foi dito anteriormente os impactos dos painéis fotovoltaicos estão associados a lixiviação de chumbo e cadmio. Wang e Xu mostram também que frações não-metálicas podem ser uma ameaça ambiental, pois mesmo após o tratamento essas frações ainda podem conter materiais pesados, retardadores de chama bromados (BFR), assim como outras substancias toxicas e perigosas. A tabela 1 pontua os impactos causados por esses compostos, e também os problemas de saúde que eles causam na corpo humano.

Tabela 1 - Compostos tóxicos e seus efeitos no ambiente e na saúde.

\begin{tabular}{|l|l|l|l|}
\hline Autor & Compostos & $\begin{array}{l}\text { Impacto } \\
\text { ambiental }\end{array}$ & $\begin{array}{l}\text { Problema de } \\
\text { saúde }\end{array}$ \\
\hline $\begin{array}{l}\text { VÉRONIQUE } \\
\text { MONIER, 2011 }\end{array}$ & Chumbo & $\begin{array}{l}\text {-Toxidade ao meio } \\
\text { ambiente. } \\
\text {-Acumulação na } \\
\text { cadeia trófica }\end{array}$ & $\begin{array}{l}\text { - Efeitos no } \\
\text { sistema nervoso, } \\
\text { reprodutor e } \\
\text { cardiovascular. }\end{array}$ \\
\hline $\begin{array}{l}\text { VÉRONIQUE } \\
\text { MONIER, 2011 }\end{array}$ & Cadmio & $\begin{array}{l}\text {-Toxidade ao meio } \\
\text { ambiente. } \\
\text { - Acumulação na } \\
\text { cadeia trófica. }\end{array}$ & $\begin{array}{l}\text { - Altamente } \\
\text { cancerígeno, } \\
\text { podendo causar } \\
\text { alterações de } \\
\text { caráter } \\
\text { fisiopatológico. }\end{array}$ \\
\hline
\end{tabular}

O chumbo é conhecido como um metal muito toxico e que tem uma grande acumulação na cadeia trófica. Quando está no corpo humano o chumbo é distribuído em tudo o corpo e no sangue, e pode ser acumulado nos ossos, causando efeitos negativos nos sistema nervoso, imunológico reprodutor e cardiovascular (VÉRONIQUE MONIER, 2011).

A primeira geração dos módulos fotovoltaicos de silício cristalino está relacionada com a lixiviação do chumbo. A quantidade de chumbo contido num painel fotovoltaico de silício é de 12,67 g, sedo que a parte que é lixiviada de chumbo no ambiente representa entre 1,64g e 11,4 g por cada modulo. (VÉRONIQUE MONIER, 2011). 
O cadmio tem uma meia vida de 30 anos e também é considerado altamente toxico e com acumulação nos organismos vivos. O cadmio é estabelecido como um agente cancerígeno que pode propicia alterações de caráter fisiopatológicos quando há uma exposição. (VÉRONIQUE MONIER, 2011).

A lixiviação envolvendo o cadmio é um risco da segunda geração de painéis fotovoltaicos, os de filmes finos. Estão inclusos em um painel cerca de 4,6 g desse metal que quando lixiviado no ambiente representa entre 0,32g $31,84 \mathrm{~g}$ por modulo. (VÉRONIQUE MONIER, 2011).

Tecnologias de reciclagem

As tecnologias existentes para a reciclagem dos painéis fotovoltaicos de silício são embasadas em tratamento físicos, químicos ou uma combinação das duas técnicas. A tabela 2 apresenta a descrição de alguns métodos que utilizam esses tratamentos (LATUNUSSA, 2012).

Tabela 1. Processos desenvolvidos para a reciclagem de painéis fotovoltaicos cristalinos

\begin{tabular}{|c|c|c|}
\hline Autor & Técnica & Tratamento \\
\hline $\begin{array}{l}\text { FRISSON, et } \\
\text { al. } 2000\end{array}$ & $\begin{array}{l}\text { A pirólise: permitiu separar } 80 \% \\
\text { das bolachas e quase } 100 \% \text { das } \\
\text { folhas de vidro. }\end{array}$ & $\begin{array}{l}\text { Químico: Processos baseados } \\
\text { em pirólise. }\end{array}$ \\
\hline $\begin{array}{l}\text { T. DOI, et al. } \\
2001\end{array}$ & $\begin{array}{l}\text { A célula de silício foi separada } \\
\text { sem qualquer dano por } \\
\text { dissolução em tricloroetileno a } \\
80^{\circ} \mathrm{C} \text { durante } 10 \text { dias. }\end{array}$ & $\begin{array}{l}\text { Químico: dissolução em } \\
\text { solventes orgânicos. }\end{array}$ \\
\hline $\begin{array}{l}\text { BOMBACH, } \\
\text { et al. } 2006\end{array}$ & $\begin{array}{l}\text { O processo alcançou um } \\
\text { rendimento de separação de } \\
\text { cerca de } 76 \% \text { das células, } \\
\text { adequado para reutilização. }\end{array}$ & $\begin{array}{l}\text { Físico e Químico: Processo } \\
\text { térmico e ácido. }\end{array}$ \\
\hline
\end{tabular}




\begin{tabular}{|c|c|c|}
\hline $\begin{array}{l}\text { GRANATA, et } \\
\text { al. } 2014\end{array}$ & $\begin{array}{l}85 \% \text { do cobre e } 62 \% \text { do silício } \\
\text { foram separados. O processo } \\
\text { permitiu recuperar até } 86 \% \text { do } \\
\text { silício com pureza muito alta. }\end{array}$ & $\begin{array}{l}\text { Químico e físico: Processo } \\
\text { com aquecimento, seguido } \\
\text { por processos químicos com } \\
\text { ácidos e álcool. }\end{array}$ \\
\hline $\begin{array}{l}\text { RIMAURO et } \\
\text { al. } 2015 \text {. }\end{array}$ & $\begin{array}{l}\text { Teve aproveitamento de } 80 \text { a } 85 \% \\
\text { do vidro, porém para alguns } \\
\text { materiais (principalmente } \\
\text { metais) teve baixa eficiência. }\end{array}$ & $\begin{array}{l}\text { Físico: processo baseado no } \\
\text { esmagamento seguido por } \\
\text { tratamento térmico. }\end{array}$ \\
\hline
\end{tabular}

Adaptado de CYNTHIA (2016)

A tabela 2 mostrou algumas das principais tecnologias utilizadas para a recuperação de materiais presentes nos painéis fotovoltaicos, e a eficiência de recuperação deles. O processo mais empregado é a utilização de métodos químicos com a ajuda de ácidos, álcoois, solventes orgânicos e a pirolise, esse processo traz uma alta eficiência na recuperação de alguns materiais que são reciclados e que podem ser utilizados posteriormente.

O processo físico apesar de ser menos utilizados que o químico, também é uma boa opção pra a recuperação desses materiais, principalmente quando estes estão associados com o tratamento químico.

Na figura 6 apresenta-se um fluxograma onde é mostrado quais são os processos que fazem parte do tratamento químico, e quais fazem parte do tratamento físico. E logo abaixo é feita a descrição da recuperação de materiais usando a combinação dos dois tratamentos. 
Figura 6 - Fluxograma das etapas de tratamento físico e químico

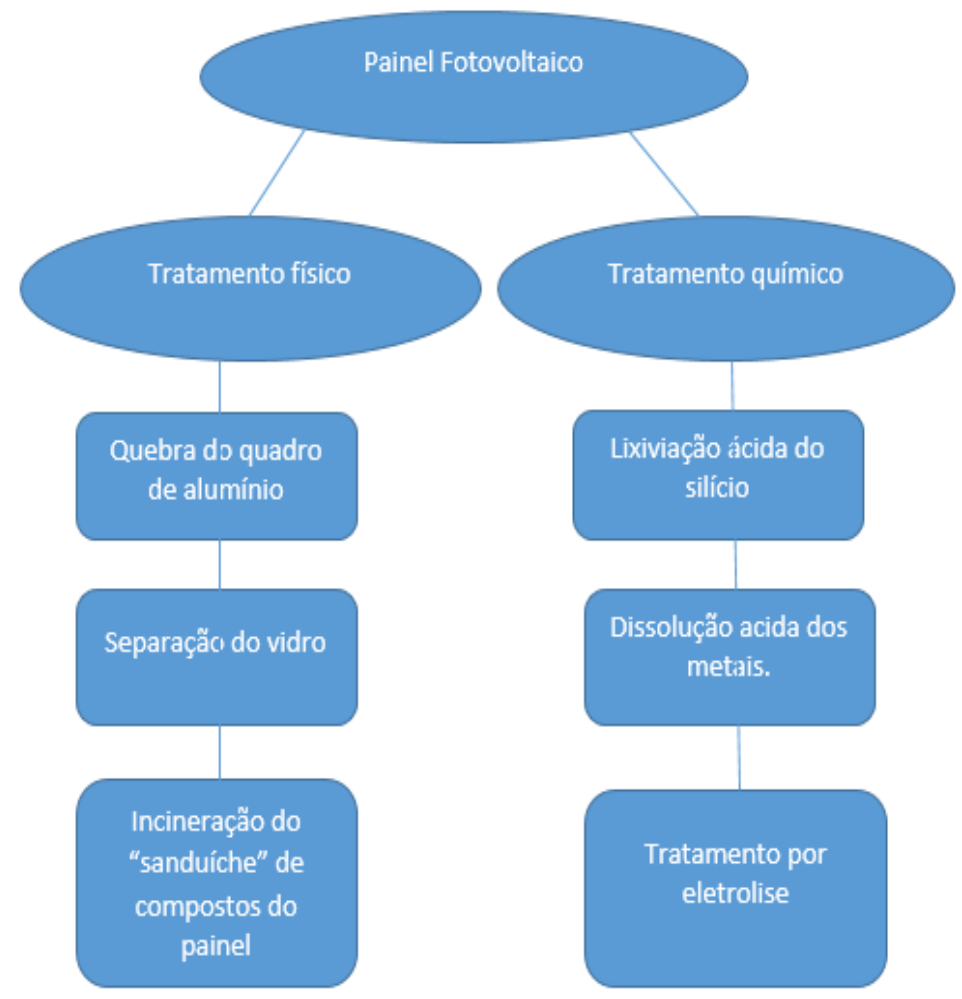

O processo de reciclagem e tratamento dos painéis fotovoltaicos começa com a desmontagem do painel. As bordas do quadro de alumínio serão cortadas e separadas dos cabos/caixa de junção, havendo assim também a separação da mesma das camada de células fotovoltaicas, vidros e polímeros (BIOIS, 2011).

Logo em seguida vem a separação do vidro das camadas restante, o que irá facilitar o processo. Para essa separação, os painéis fotovoltaicos são aquecidos por um sistema misto de infravermelho de onda média e curta, para que haja um desprendimento mecânico. O resultado será pedaços de vidro que passara por um processo posterior de refinação (CELLURA et al, 2012).

O restante do "sanduiche" de composto do painel e levado para uma incineradora, sendo que o resultado de tal incineração é um composto de cinza, que contem silício e outros metais. Essa cinza vai para um processo de tratamento onde passa por peneiração e o resíduo desse processo de peneiração passa por um outro processo, que é a de lixiviação ácida (GRANATA et, al. 2014).

O processo de lixiviação ácida tem o objetivo de fazer a separação do silício do restante dos outros metais presentes na cinza, espera-se que a lixiviação ácida recupere $95 \%$ do silício como metal de silício em grau metalúrgico (ALSEMA et. al, 
2006). O restante dos metais são dissolvidos na solução ácida e sucessivamente tratada por eletrolise. Há uma recuperação de prata e cobre com eficiência de 95\%, e o que não serviu para ser aproveitado é encaminhado para um aterro para disposição final (KIM et. al, 2012).

Benefícios da reciclagem do painéis fotovoltaicos ao meio ambiente

A energia solar é uma abundante e permanente, renovável, não polui e nem prejudica o ecossistema além de ser sustentável, no entanto, isso não quer dizer que a mesma não causa nenhum impacto ao meio ambiente. Porém o tipo de impacto causado é apenas impactos localizados, e que podem ser tratados imediatamente após ocorridos (SUNERGIA, 2018).

Alguns dos benéficos que podem ser pontuados com a utilização e a reciclagem da energias fotovoltaicas são:

- Redução das emissão de gases do efeito estufa;

- Redução de gases como óxido de nitrogênio, óxido de enxofre e monóxido de carbono;

- A manutenção requerida é mínima;

- Decaimento do custo para implantação da energia;

- Economicamente viável, entre outros.

\section{CONCLUSÃO}

Pode-se concluir que a reciclagem dos painéis fotovoltaicos tem ser tornado importante, devido ao grande aumento dos resíduos do modulo fotovoltaico. E apesar de as pesquisas de tecnologias para essa reciclagem estar em evolução, algumas já empregadas como a tecnologia de tratamento químico e físico para a recuperação de alguns materiais desses módulos é bem promissora, além das vantagens que sem tem com a redução dos gases de efeito estufa. 


\section{REFERÊNCIAS BIBLIOGRÁFICAS}

ANDREA BETTANIN. O uso de tiossulfato para a recuperação de prata na reciclagem de módulos fotovoltaicos. Universidade Federal do Rido Grande do Sul, 2017.

Alsema, E. A., Nieuwlaar, E. Energy viability of photovoltaic systems. Department of Science, Technology and Society, Utrecht University Padualaan 14, NL-3584 CH Utrecht, The Netherlands. Received 24 May 2000.

Bio Intelligence Service (Biols), Study on photovoltaic panels supplementing the impact assessment for a recast of the WEEE directive - Final report, 2011.

BROUWER, Karen Ann; GUPTA, Chaya; HONDA, Shelton. Methods and Concerns for Disposal of Photovoltaic Solar Panels. 2011. 77 f. Dissertação (Mestrado) - Scien Cyrs, William, et al. Landfill waste and recicling: Use of a screening-level risk assessment tool for end-of-life cadmium telluride (CdTe) thin-film photovoltaic (PV) panels energy policy, 68, 524-533, 2014.

CRESESB. Energia Solar Princípios e Aplicações. Centro de Referência para Energia Solar e Esólica Sérgio de Salvo Brito. Disponível em: <http://www.wbdg.org/resources/bipv.php>. Acesso em: 12 de setembro de 2016.

CHIVELET, N. M. Técnicas de Vedação Fotovoltaica na Arquitetura: Bookman. Porto Alegre, 2010.

Cynhia E. L, Latanussa, Fulvio Ardete, Gian Andrea Blengini, Lucia Mancini. Life Cycle Assessment of an innovative recycling process for crystalline silicon photovoltaic panels. Solar Energy Materials \& Solar Cells 156(2016) 101-111.

DIAS, Pablo Ribeiro. Caracterização e Reciclagem de Materiais de Módulos Fotovoltaicos.2015. 83 f. Dissertação (Mestrado) - Curso de Engenharia de Minas, 2015.

E.A. Alsema, M.J. de Wild-Scholten, V.M. Fthenakis, Environmental impacts of PV electricity generation - a critical comparison of energy supply options, in: Dresden, Germany, 4-8 September, 2006.

FRAIDENRAICH, N.; LYRA, F. Energia solar: fundamentos e tecnologias de conversão heliotérmica e fotovoltaica.: Ed universitária da UFPE. Recife, 1995.

G. Granata, F. Pagnanelli, E. Moscardini, T. Havlik, L. Toro, Recycling of photo- voltaic panels by physical operations, Sol. Energy Mater. Sol. Cells 123 (2014) 239-248. 
Giacchetta, G., Leporini, M., Marchetti, B. Evaluation of the environmental benefits of new high value process for the management of the end of life oh thin film photovoltaic modules. Journal of Cleaner Production, 51, 214-224, Jan. 2013.

H.C. Kim, V. Fthenakis, J.K. Choi, D.E. Turney, Life cycle greenhouse gas emis- sions of thin-film photovoltaic electricity generation: systematic review and harmonization, J. Ind. Ecol. 16 (S1) (2012) S110-S121.

Jeongeun Shin, Jongsung Park, Nochang Park. A method to recycle silicon wafer from end-of-life photovoltaic module and solar panels by using recycled silicon wafers. Solar Energy Materials \& Solar Cells 162 (2017).

Jorge Ignacio Andreotti. PLANO SOLAR SAN JUAN- Fabricação de Painéis Solares. ACESSADO EM <http://ingenieroandreotti.blogspot.com.br/2013/01/plan-solar-sanjuan-fabricacion-de.html>, 2018.

Kang, S., Yoo, S., Lee, J., Boo, B., Ryu, H., 2012. Experimental investigations for recycling of silicon and glass from waste photovoltaic modules. Renew. Energy 47, 152-159.

Kiddee, P., Naidu, R., Wong, M.H., 2013. Electronic waste management approaches: an overview. Waste Manage. 33, 1237-1250.

LATUNUSSA Cynthia E.L., ARDENTE Fulvio, BLENGINI Gian Andrea, MANCINI Lucia. Life Cycle Assessment of an innovative recycling process for crystalline silicon photovoltaic panels. European Commission, Joint Reseaech Centre (JRC), Institute for Environmentand Sustainability (IES), via Enrico Fermi 2749, 2012.

M. Cellura, A. Di Gangi, S. Longo, A. Orioli, Photovoltaic electricity scenario analysis in urban contests: an Italian case study, Renew. Sustain. Energy Rev. 16 (2012) 2041-2052.

RÜTHER, R. Edifícios solares fotovoltaicos: o potencial da geração solar fotovoltaica integrada a edificações urbanas e interligada à rede elétrica pública no Brasil: Editora UFSC/LABSOLAR. Florianópolis, 2004.

SOLAR POWER EUROPE. Global Market Outlook for Photovoltaics until 2017. Belgium, 2015.

SANTOS, Augusto Cesar da S., SANTOS, Marcelo Paulo de Lima, SILVA, Samila Batista. Os benefícios do uso de painéis solares para o meio ambiente. Revista de divulgação do Projeto Universidade Petrobras e IF Fluminense v. 1, p. 373-376, 2010.

SUNERGIA. Impacto da energia solar no meio ambiente/ benefícios da energia fotovoltaica. Disponível em <www. sunergia.com.br/blog/impacto-da-energia-solarno-meio-ambiente-beneficios-da-energia-fotovoltaica/> Acessado em 07 de maio de 2018. 
VILLALVA, M.; GAZOLI, J. Energia solar fotovoltaica: conceitos e aplicações. São Paulo: Erica, 2012.

VÉRONIQUE MONIER (France). European Commision. Study on Photovoltaic Panels Supplementing the Impact Assessment for a Recast of the WEEE Directive. Paris, 2011.

WU, L., TIAN, W., JIANG, X. Silicon-based solar cell system with a hybrid PV module. Solar Energy Materials \& Solar Cells 87 (2005) 637- 645.

Wang, R., Xu Z. Recycling of non-metallic fractions from waste electrical and electrnic equipment (WEEE): A review. Waste Management. 34, 1455-1469. 2014. 